\title{
A PRELIMINARY SURVEY ON THE LEVEL OF AWARENESS OF DENGUE CONTROL PROGRAMMES AMONG RESIDENCES IN KUALA TERENGGANU
}

\author{
HAN SHIOU FENG ${ }^{\mathrm{A}}$, NUR AIDA HASHIM ${ }^{\mathrm{B}}$, NUR ADILA KAMARUDDIN ${ }^{\mathrm{C}}$, NUR SYAHIDA \\ WADHIHAH KAMARUDIN ${ }^{\mathrm{D}}$ AND NORASMAH BASARI ${ }^{\mathrm{E} *}$
}

${ }^{a, c, d, e}$ Faculty of Science and Marine Enviroment, Universiti Malaysia Terengganu, 21030 Kuala Nerus, Terengganu

${ }^{b}$ Faculty of Fisheries and Food Science, Universiti Malaysia Terengganu, 21030 Kuala Nerus, Terengganu

*Corresponding author: enorasmah@umt.edu.my

\begin{abstract}
Dengue fever and dengue haemorrhagic fever are diseases caused by dengue virus transmitted by Aedes mosquitoes. Dengue fever has caused a high rate of mortalities among Malaysians every year. Even though many campaigns had been conducted by the government to reduce dengue cases, the number of infected people in this country is still high. We conducted this survey to determine the status of dengue fever awareness among residents in Kuala Terengganu. For data collection, face-to-face interviews were conducted, and a questionnaire was administered. There were three categories of respondents, namely urban area residents, rural area residents and university students. Results showed that respondents across the three groups were knowledgeable regarding dengue fever issues and there was no significant difference between the three categories of respondents in the number of residents who had been involved in dengue awareness programmes. However, most of the respondents regarded the dengue awareness programmes as moderately effective and could be overcome if prevention efforts and approaches were being carried out on a continuous basis.
\end{abstract}

Keywords: Mosquitoes, Aedes, health campaigns, dengue virus, questionnaire.

\section{Introduction}

Dengue fever is one of the major diseases in Malaysia caused by Aedes mosquitoes namely Ae. aegypti and Ae. albopictus. Aedes aegypti breeds almost exclusively in containers in and around the house (Chen et al., 2009; WanNorafikah et al., 2012; Saleeza, 2013; Basari et al., 2016) and feeds mainly indoors or in the immediate neighbourhood during the day. Furthermore, Ae. albopictus is a forest species that has become adapted to rural, suburban and urban areas and is a competent vector for at least 22 arboviruses including dengue (Gratz, 2004). A study by Brady et al. (2012) estimated that 3.9 billion people in 128 countries were at risk of infection with dengue viruses.
Dengue fever becomes a public health problem in Peninsular Malaysia since the major outbreak of the disease in 1974 (Ministry of Health, 1980; Wallace et al., 1980). According to the statistics issued by the Malaysian Ministry of Health (KKM) in 2010 when this study was conducted, a total of 27,989 cases of dengue fever had been reported in Peninsular Malaysia and the numbers increased in 2011 with 29,255 cases. Various activities such as campaigns and publicity at the state level, Aedes surveillance, fogging activities, community clean-up activities and school cleanliness programmes had been carried out by cleaning and removing potential Aedes breeding habitats. All these campaigns and activities were conducted to control the disease and increase the awareness among residents on the risks of dengue fever 
(Ministry of Health, 1998). However, it was unknown how far the campaigns and activities left an impact on the residents as information on the status of dengue fever awareness among residents in Kuala Terengganu then was lacking. Thus, there was a need to conduct a survey on the effect of these activities and the status of dengue fever awareness among residents. This questionnaire-based survey was aimed to have a better understanding of the perception of Malaysian residents towards dengue fever problems.

\section{Materials and Methods}

\section{Study Sites}

A questionnaire-based survey was conducted in Bandaraya Kuala Terengganu. Kuala Terengganu is the largest city as well as the state and royal capital of Terengganu state, Malaysia. This study was conducted from August 2010 until April 2011.

The study site was divided into two parts: rural (villages) and urban (town) areas. In the rural areas, seven villages were choosen; i.e, Kampung Pak Tuyu, Kampung Pak Jin, Kampung Gong Datok, Kampung Kubang Badak, Kampung Gong Badak, Kampung Tok Jembal and Kampung Telaga Batin while in the town areas, respondents were chosen randomly from Kampung Tanjung, Kampung Tiong, Kampung Paya, Kampung Ladang Tok Pelam, Kampung Batas Baru, Pulau Kambing, Kampung Bukit Kecil and Kampung Batu Buruk.

\section{Data Collection}

A questionnaire was designed to collect the data related to the dengue fever awareness among residents in Kuala Terengganu. Each set of questionnaires consisted of nine questions with a mix of close-ended, likert and dichotomous types of questions. This study collects quantitative data from three categories of respondents (i.e, residents from rural (villages) area, urban (town) area and among the third-year students from
Universiti Malaysia Terengganu (UMT)). For rural and urban residents, seven to eight houses were chosen randomly per villages and town areas. A face-to-face interview based on the questions prepared earlier in the questionnaire forms were conducted with all respondents aged between 20 to 40 years old. In total, 150 questionnaire forms were distributed that represents about $10 \%$ of the total population for all categories (50 forms from rural, urban and University students, respectively).

\section{Statistical Analysis}

A Chi-squared test was used to analyse the frequency of respondents' response on each of the question asked. All the statistical data analyses were performed using Statistical Package for the Social Sciences (SPSS) programme version 24.

\section{Results and Discussion}

Overall, 85\% respondents revealed that they were aware with dengue fever issues (Figure 1a). Most of the respondents obtained the information on dengue fever through television (47\%) and for some their sources of information came from family members and relatives $(21 \%)$. There was no significant difference among the three groups of respondents on how they received or obtained information on dengue fever indicating that television plays an important role in spreading information to residents living in both rural and urban areas as well as to University students $\left(\chi^{2}=8.446, \mathrm{df}=6, \mathrm{P}=0.207\right.$; Figure $\left.1 \mathrm{~b}\right)$. The respondents also identified that containers are the most common place of mosquitoes' breeding habitat $(42 \%)$ while used tyres ranked second which is $26 \%$ (Figure 1c). In terms of the knowledge regarding the symptoms of dengue fever, $31 \%$ out of 150 respondents suggested fever, abdominal pains and red spots as the most common symptoms (Table 1). Respondents across the three categories had the same level of knowledge regarding the symptoms of dengue fever $\left(\chi^{2}=2.442\right.$, df $\left.=2, \mathrm{P}=0.295\right)$. Most of the respondents across the three categories were found to be knowledgeable 
or involved in the dengue fever control and awareness programmes $(73 \%)$ and they rated the programmes as moderately effective $(60 \%)\left(\chi^{2}\right.$ $=0.467, \mathrm{df}=2, \mathrm{P}=0.792)$. Fifty nine percent of respondents said that they would share all the information regarding dengue fever with their family members and friends. a)

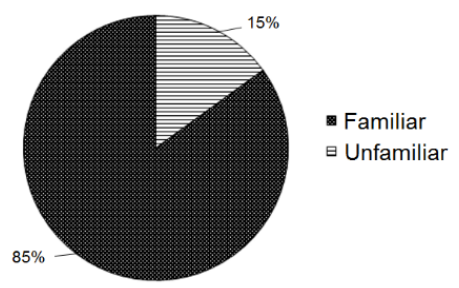

c)

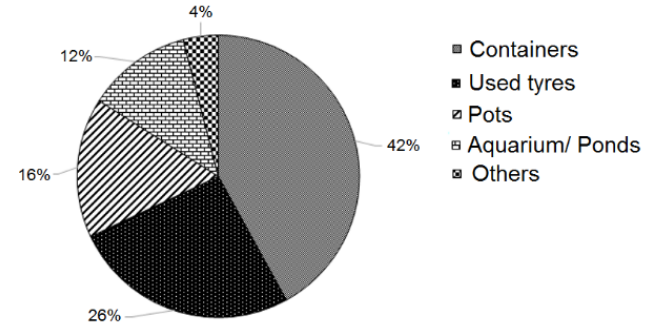

b)

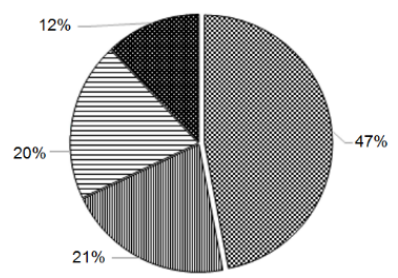

Television

Family members/

relatives

日 Newspapers

‥ㅁ Websites

Figure 1: (a) Percentage of respondents on the familiarity of dengue fever issue. (b) Percentage of respondents who revealed ways of getting information of dengue diseases. (c) Number of respondents revealed the mosquitoes's breeding habitats based on their knowledge and experience.

Table 1: Survey on attitude and knowledge of respondents toward dengue fever issues.

\begin{tabular}{|c|c|c|c|c|c|}
\hline \multirow[t]{2}{*}{ Questions } & \multirow[t]{2}{*}{ Answer options } & \multicolumn{3}{|c|}{ Respondents } & \multirow[b]{2}{*}{$\begin{array}{r}\text { Total } \\
(* * \%)\end{array}$} \\
\hline & & $\begin{array}{l}\text { Urban } \\
(* \%)\end{array}$ & $\begin{array}{l}\text { Rural } \\
(* \%)\end{array}$ & $\begin{array}{l}\text { Students } \\
(* \%)\end{array}$ & \\
\hline \multirow[t]{7}{*}{ Symptoms of dengue fever } & Fever & 24 & 26 & 16 & 22 \\
\hline & Fever and abdominal pains & 22 & 2 & 20 & 15 \\
\hline & Fever and red spots & 20 & 22 & 16 & 19 \\
\hline & Fever, abdominal pain and & 22 & 36 & 34 & 31 \\
\hline & red spots & 8 & 10 & 6 & 8 \\
\hline & $\begin{array}{l}\text { Fever, abdominal pain and } \\
\text { vomiting }\end{array}$ & 4 & 4 & 8 & 5 \\
\hline & $\begin{array}{l}\text { Fever, abdominal pain and } \\
\text { gum bleeding }\end{array}$ & & & & \\
\hline \multirow{2}{*}{$\begin{array}{l}\text { Knowledge on any dengue fever } \\
\text { control and awareness programmes } \\
\text { carried out by government }\end{array}$} & Yes & 70 & 72 & 76 & 73 \\
\hline & No & 30 & 28 & 24 & 27 \\
\hline \multirow[t]{3}{*}{ Effectiveness of the programmes } & Very effective & 20 & 19 & 18 & 19 \\
\hline & Moderately effective & 60 & 61 & 58 & 60 \\
\hline & Not effective & 20 & 20 & 24 & 21 \\
\hline Information sharing regarding & Yes & 54 & 66 & 58 & 59 \\
\hline $\begin{array}{l}\text { dengue fever with family members } \\
\text { and friends }\end{array}$ & No & 46 & 34 & 42 & 41 \\
\hline
\end{tabular}

\footnotetext{
*Percentage of 50 respondents
}

**Percentage of 150 respondents 
The study revealed that most Kuala Terengganu residents (respondents) were familiar with dengue fever due to the publicity by the Ministry of Health. Based on the survey, the majority of the respondents across the three groups were knowledgeable and well exposed to the issue of dengue fever in Kuala Terengganu. This may be due to the constant occurrence of dengue cases in Kuala Terengganu, thus awareness and control programmes were conducted continuously in this state as well as in the whole country. Besides, there were regular inspections of mosquito breeding sites by the Health Inspectors from the Ministry of Health (Rohani Wan Hussain, Pers. Comm.). As a result, rural area residents were more exposed to the awareness and control programmes that were conducted by the government.

Several questions were asked during the interview to evaluate the respondents' knowledge on dengue fever and Aedes breeding sites. Based on the survey, most of the respondents could give accurate and reasonable answers. They were exposed to such information through various media such as television, newspapers, websites, family members and friends. Television was the most effective media to convey dengue fever issues because almost every family had at least one television set at home and watching television was one of their favourite pastimes. Some respondents revealed that they acquired the knowledge on dengue fever through experience as they had dengue fever before.

Most of the respondents were aware of dengue awareness and control programmes. According to respondents, fogging activities were the most common activity carried out by the government. Normally, fogging activities would be carried out when there were dengue fever cases in that particular area. Due to this, some respondents revealed that fogging activities were only focusing on the areas affected by dengue fever. Instead, it should be carried out in all areas, making it more comprehensive. This one reason highlighted as to why most of the respondents regarded the programmes as moderately effective. Besides, there were also other campaigns being carried out to increase the awareness among the residents of Kuala Terengganu. According to some rural area residents, talks were given by officers from the Kuala Terengganu Ministry of Health regarding dengue fever issues in Kuala Terengganu. This activity was beneficial to residents because they could be updated with the latest information regarding the current status of dengue fever cases in Kuala Terengganu and ways to prevent dengue infection. One of the dengue awareness programmes conducted by the Kuala Terengganu Ministry of Health was called 'Take 10 Minutes Every Friday'. This programme was to encourage residents to inspect their homes once a week to eliminate any potential Aedes breeding sites. Moreover, the Ministry of Health also provided insecticide which was used to eliminate and control Aedes mosquitoes (Shamsol Bahri, Pers. Comm.). Furthermore, the community clean-up activities were held to foster good habits of keeping the housing area clean and free of Aedes breeding sites.

Residents living in any areas (villages or towns) should take responsibility for the dengue fever issues and play their roles in preventing the outbreak of dengue fever in Kuala Terengganu. Firstly, resident must maintain cleanliness of their homes and surrounding areas to make sure that there were no potential breeding sites for Aedes mosquitoes for example and they should scour and empty watering containers and vases at least once a week. The government could carry out campaigns through a short video or advertisement regarding dengue fever more frequently through television since it is the main media for residents. However, since the medium of information transfer has been changed nowadays with the widely used of smartphones, social media such as Facebook, Instagram, Twitter and other smartphone applications, these mediums may become the most effective way to spread the information. The government should create more comprehensive campaigns so that more residents could be exposed to Aedes and dengue fever information. Residents should share information regarding dengue fever with their family members and friends in order to increase awareness among residents. 


\section{Conclusion}

From to the survey conducted, it can be concluded that both rural and urban residents as well as University students were considered as knowledgeable regarding dengue fever issues in Kuala Terengganu. This is due to more awareness and control programmes being carried out in the areas. However, most respondents in Kuala Terengganu still regarded the dengue awareness programme as moderately effective. The government and residents should play their roles in preventing the occurrence of dengue cases by making sure that no breeding places for Aedes were readily available around their premises for Aedes to breed. The government could also conduct more awareness programmes for the public. Although the data presented in this study was gathered in 2010 to 2011, we believe that this survey would provide a better picture of the level of awareness among residents in Kuala Terengganu on Aedes and the dengue campaigns conducted by the government and eventually could help in planning on future dengue awareness campaigns.

\section{Acknowledgements}

We would like to thank all the officers of Kuala Terengganu Department of Health, especially Mr. Shamsol Bahri Bin Hamzah and Mrs. Rohani Binti Wan Hussain for their willingness to share and provide information on dengue issues in Kuala Terengganu through face-to-face interview.

\section{References}

Basari, N., Aiman Syazwan, H., Mohd Zairi, Z., \& Nur Aida, H. (2016). Larval Distributions and breeding habitats of Aedes aegypti and Ae. albopictus in Kuala Terengganu. Tropical Biomedicine, 33(3), 1-8.
Brady, O, J., Gething, P, W., Bhatt, S., Messina, J, P., Brownstein, J, S., Hoen, A, G. (2012). Refining the global spatial limits of dengue virus transmission by evidencebased consensus. PLoS Neglected Tropical Diseases. 6(8), e1760.https://doi:10.1371/ journal.pntd.0001760.

Chen, C, D., Lee, H, L., Stell-Wong, S, P., Lau, K, W., \& Sofian-Azirun, M. (2007). Container survey of mosquito breeding sites in a university campus in Kuala Lumpur, Malaysia. Dengue Bulletin 33,187-193.

Gratz, N, G. (2004). Critical review of the vector status of Aedes albopictus. Medical and Veterinary Entomology 18(3), 215-27.

Ministry of Health, Malaysia. Annual report 1980, 1998, 1999, 2010. Retrieved from http://idengue.arsm.gov.my/

Saleeza, S, N, R., Norma-Rashid, Y., Azirun, M, S. (2013). Mosquito species and outdoor breeding places in residential areas in Malaysia. Southeast Asian Journal of Tropical Medicinal Public Health 44(6), 963-969.

Wallace, H, G., Lim, T, W., Rudnick, A., Knudsen, A, B., Cheong, W, H., \& Chew, V. (1980). Dengue hemorrhagic fever in Malaysia: the 1973 epidemic. Southeast Asian Journal of Tropical Medical Public Health 11(1), 1-13.

Wan-Norafikah, O., Nazni, W, A., Noramiza, S., Shafa'Ar-Ko'Ohar., Heah, S, K., NorAzlina, A, H., Khairul-Asuad, M., Lee, H, L. (2012). Sains Malaysiana 41(10), 13091313. 
